\section{JTI}

JOURNAL OF

TRAUMA AND INJURY

\title{
Part 3. Clinical Practice Guideline for Airway Management and Emergency Thoracotomy for Trauma Patients from the Korean Society of Traumatology
}

\author{
Chan Yong Park, M.D., Ph.D. ${ }^{1}$, O Hyun Kim, M.D., Ph.D. ${ }^{2}$, \\ Sung Wook Chang, M.D. ${ }^{3}$, Kang Kook Choi, M.D., Ph.D. ${ }^{4}$, Kyung Hak Lee, M.D. ${ }^{5}$, \\ Seong Yup Kim, M.D. ${ }^{6}$, Maru Kim, M.D., Ph.D. ${ }^{7}$, Gil Jae Lee, M.D., Ph.D. , \\ Korean Society of Traumatology (KST) Clinical Research Group \\ ${ }^{1}$ Department of Trauma Surgery, Wonkwang University Hospital, Iksan, Korea \\ ${ }^{2}$ Department of Emergency Medicine, Yonsei University Wonju College of Medicine, \\ Wonju, Korea \\ ${ }^{3}$ Department of Thoracic and Cardiovascular Surgery, Trauma Center, Dankook University \\ Hospital, Cheonan, Korea \\ ${ }^{4}$ Department of Traumatology, Gachon University College of Medicine, Incheon, Korea \\ ${ }^{5}$ Department of Orthopedic Surgery, National Medical Center, Seoul, Korea \\ ${ }^{6}$ Department of Surgery, Wonju Severance Christian Hospital, Yonsei University Wonju \\ College of Medicine, Wonju, Korea \\ ${ }^{7}$ Department of Trauma Surgery, Uijeongbu St. Mary's Hospital, College of Medicine, \\ The Catholic University of Korea, Uijeongbu, Korea
}

\section{Correspondence to}

Gil Jae Lee, M.D., Ph.D.

Department of Traumatology, Gachon University Gil Medical Center, Gachon University College of Medicine, 783 Namdong-daero, Namdong-gu, Incheon 21556, Korea

Tel: $+82-32-460-3010$

Fax: $+82-32-460-2372$

E-mail: nonajugi@gilhospital.com

The following key questions and recommendations are presented herein: when is airway intubation initiated in severe trauma? Airway intubation must be initiated in severe trauma patients with a GCS of 8 or lower (1B). Should rapid sequence intubation (RSI) be performed in trauma patients? RSI should be performed in trauma patients to secure the airway unless it is determined that securing the airway will be problematic (1B). What should be used as an induction drug for airway intubation? Ketamine or etomidate can be used as a sedative induction drug when RSI is being performed in a trauma patient (2B). If cervical spine damage is suspected, how is cervical protection achieved during airway intubation? When intubating a patient with a cervical spine injury, the extraction collar can be temporarily removed while the neck is fixed and protected manually (1C). What alternative method should be used if securing the airway fails more than three times? If three or more attempts to intubate the airway fail, other methods should be considered to secure the airway (1B). Should trauma patients maintain normal ventilation after intubation? It is recommended that trauma patients who have undergone airway intubation maintain normal ventilation rather than hyperventilation or hypoventilation $(1 \mathrm{C})$. When should resuscitative thoracotomy be considered for trauma patients? Resuscitative thoracotomy is recommended for trauma patients with penetrating injuries undergoing cardiac arrest or shock in the emergency room (1B).

Keywords: Airway management; Thoracotomy; Practice guideline; Wounds and injuries

Copyright $(2020$ The Korean Society of Trauma

This is an Open Access article distributed under the terms of the Creative Commons Attribution Non-Commercial License (http://creativecommons.org/licenses/by-nc/4.0/) which permits unrestricted noncommercial use, distribution, and reproduction in any medium, provided the original work is properly cited. 
Based on the revised recommendations, the final recommendations were confirmed after collecting opinions from trauma experts, experts from the Korean Society of Traumatology, and research method experts using the Delphi technique (Table 1).

\section{IN WHICH CASES SHOULD AIRWAY IN- TUBATION BE PERFORMED IN PATIENTS WITH SEVERE TRAUMA?}

\section{Recommendation}

Airway intubation must be initiated in severe trauma patients with a Glasgow Coma Score (GCS) of 8 or lower (1B).

\section{Absolute indications}

- Apnea or gasping

- When hypoxia persists $\left(\mathrm{SpO}_{2}<90 \%\right)$ in a patient with no signs of tension pneumothorax despite being given adequate oxygen

- Severe traumatic brain injury (GCS $<9)$

\section{When airway intubation must be considered}

- Hemodynamic instability related to trauma (systolic blood pressure $<90 \mathrm{mmHg}$ )

- Respiratory failure accompanied by severe thoracic injury (breath rate $>29$ breaths/minutes

\section{Evidence summary}

The most effective method to secure oxygen supply is through airway intubation according to the European guidelines on trauma cases [1-3]. Airway intubation is indicated in patients with a GCS lower than 9 and traumatic brain injury [4]. According to the Advanced Trauma Life Support (ATLS) and Eastern Association for the Surgery of Trauma (EAST) guidelines, patients with a GCS of 8 or lower must be intubated as soon as the opportunity presents $[1,5]$. In patients with brain injury accompanied by multiple injuries, low blood pressure and hypoxia interact, resulting in death [6-10]. Several studies have reported that airway intubation has a positive effect in patients with traumatic brain injury [11-14]. However, not all studies produced positive results due to differences across various facilities and systems [3,15-23]. The EAST group has pointed out that no randomized controlled tri-

Table 1. Scores from the Delphi technique (Likert scale 1-9)

\begin{tabular}{|c|c|c|c|}
\hline Key question & Recommendation & Mean & SD \\
\hline $\begin{array}{l}\text { In what cases should airway intubation be performed } \\
\text { in patients with severe trauma? }\end{array}$ & $\begin{array}{l}\text { Airway intubation must be initiated in severe trauma patients with a GCS } \\
\text { of } 8 \text { or lower (1B). }\end{array}$ & 8.4 & 0.9 \\
\hline Should RSI be performed in trauma patients? & $\begin{array}{l}\text { RSI should be performed in trauma patients to secure the airway unless it } \\
\text { is determined that securing the airway will be problematic (1B). }\end{array}$ & 7.4 & 1.3 \\
\hline $\begin{array}{l}\text { What should be used as an induction drug for airway } \\
\text { intubation? }\end{array}$ & $\begin{array}{l}\text { Ketamine or etomidate can be used as a sedative induction drug when RSI } \\
\text { is being performed in a trauma patient (2B). }\end{array}$ & 8.0 & 0.9 \\
\hline $\begin{array}{l}\text { If cervical spine damage is suspected, how is cervical } \\
\text { protection achieved during airway intubation? }\end{array}$ & $\begin{array}{l}\text { When intubating a patient with a cervical spine injury the extraction collar } \\
\text { can be temporarily removed while the neck is fixed and protected man- } \\
\text { ually (1C). }\end{array}$ & 8.0 & 0.8 \\
\hline $\begin{array}{l}\text { What alternative method should be used if securing } \\
\text { the airway fails more than three times? }\end{array}$ & $\begin{array}{l}\text { If three or more attempts to intubate the airway fail, other methods should } \\
\text { be considered to secure the airway (1B). }\end{array}$ & 8.3 & 0.6 \\
\hline $\begin{array}{l}\text { Should trauma patients maintain normal ventilation } \\
\text { after intubation? }\end{array}$ & $\begin{array}{l}\text { It is recommended that trauma patients who have undergone airway } \\
\text { intubation maintain normal ventilation rather than hyperventilation or } \\
\text { hypoventilation (1C). }\end{array}$ & 8.2 & 0.8 \\
\hline $\begin{array}{l}\text { When should resuscitative thoracotomy be consid- } \\
\text { ered for trauma patients? }\end{array}$ & $\begin{array}{l}\text { Resuscitative thoracotomy is recommended for trauma patients with pen- } \\
\text { etrating injuries undergoing cardiac arrest or shock in the emergency } \\
\text { room (1B). }\end{array}$ & 8.1 & 0.8 \\
\hline
\end{tabular}

SD: standard deviation, GCS: Glasgow Coma Score, RSI: rapid sequence intubation, MTP: massive transfusion protocol. 
als have been conducted on this question, and that there is no research on alternative methods. Although the exact scientific basis for airway intubation has not been fully established, it is implemented in real-world settings and strongly recommended in hypoxia patients $[2,24]$. In patients with thoracic injury showing symptoms of hypoxemia without tension pneumothorax, intubation must be performed $[1,24]$. In addition to the recommendations of ATLS and Prehospital Trauma Life Support, many studies have reported that intubation was performed at the prehospital stage or relatively quickly within 2 hours of hospitalization with positive results [25-30].

In a prospective multicenter observational study that compared the recovery of trauma and non-trauma patients who had been intubated, it was determined that trauma patients recovered significantly more quickly and efficiently than their non-trauma counterparts [31]. In another prospective multicenter observational study, it was shown that the most common cause of intubation was injury to the head and that rapid sequence intubation (RSI) was the most preferred method of airway management. That study also noted that the survival rate increased when nerve blockers were used [32]. Even if the criteria for intubation are not initially met, losing the chance for intubation later on can be detrimental, requiring attention and further monitoring [33]. In a 2011 meta-analysis, the safety of pre-hospital intubation was studied and significant correlations were found between pre-hospital intubation and safety outcomes [34].

\section{SHOULD RSI BE PERFORMED IN TRAUMA PATIENTS?}

\section{Recommendation}

RSI should be performed in trauma patients to secure the airway unless it is determined that securing the airway will be problematic (1B).

\section{Evidence summary}

Airway intubation for severe trauma patients must be systematic. Inappropriate intubation will lead to increased morbidity and mortality rates. A prospective study compared intubation performed in emergency situation
( $\mathrm{n}=241)$ or non-emergency situation $(\mathrm{n}=2,136)$, and found that emergency patients were significantly more likely to have severe hypoxia $\left(\mathrm{SpO}_{2}<70 \%: 25 \%\right.$ vs. $4.4 \%$, $p<0.001$ ), reflux ( $25 \%$ vs. $2.4 \%, p<0.001$ ), aspiration ( $12.8 \%$ vs. $0.8 \%, p<0.001)$, bradycardia $(21.3 \%$ vs. $1.5 \%$, $p<0.001$ ), arrhythmia (23.4 vs $4.1 \%, p<0.001)$, and cardiac arrest $(10.2$ vs $0.7 \%, p<0.001)$ [35].

In trauma patients, the airway must be kept safe and RSI should be performed as soon as possible in order to minimize the possibility of aspiration. In a retrospective study that examined 1,941 emergency patients for 18 months, the number of attempts needed to succeed in airway intubation differed drastically when RSI was performed. The cumulative success rate of three attempts to intubate a hemodynamically stable patient differed significantly when no medication was used $(58 \%, 69 \%$, $73 \%)$, medication was used $(44 \%, 63 \%, 75 \%)$, and RSI was performed $(56 \%, 81 \%, 91 \%)$ [36]. In other studies it was shown that when a muscle relaxant was not used, the likelihood of intubation failing significantly increased. Accordingly, the key to successful intubation is performing RSI with the addition of appropriate medication [37].

\section{Acceptability and applicability}

Many domestic trauma centers, emergency medical centers, and emergency rooms are already performing RSI. RSI is not difficult to apply and is deemed acceptable.

\section{WHAT SHOULD BE USED AS AN INDUC- TION DRUG FOR AIRWAY INTUBATION?}

\section{Recommendation}

Ketamine or etomidate can be used as a sedative induction drug when RSI is being performed in a trauma patient (2B).

\section{Evidence summary}

The side effects of etomidate must be examined carefully. In a retrospective study that examined the national trauma registry, the use of etomidate was shown to have potential adverse effects. In that study, etomidate was administered to 35 of 94 trauma patients (37\%) during rapid continuous tracheal intubation. There were no 
significant differences between the group that received etomidate and the group that did not receive etomidate in terms of demographic characteristics (age, 36 vs. 41 years), cause of trauma, and severity (injury severity score, 26 vs. 22). Etomidate was associated with an increased risk of acute respiratory distress syndrome and multiple organ failure after adjusting for physiological indicators, injury severity, and blood transfusion (adjusted odds ratio [OR] 3.9; 95\% confidence interval [CI] 1.24-12.0). In trauma patients who were administered etomidate once, the hospitalization period was longer (19 days vs. 22 days, $p<0.02$ ), the duration of airway intubation was longer (11 days vs. 14 days, $p<0.04$ ), and ICU stay was also longer (13 days vs. 16 days, $p<0.02$ ) [38].

In another prospective randomized study, etomidate and succinylcholine or fentanyl, midazolam, and succinylcholine were used for rapid continuous tracheal intubation in trauma patients at a level I trauma center [39]. In that study, adrenocorticotropic hormone tests were also performed and basal blood cortisol concentrations were recorded prior to use of sedation-inducing drugs. When all 30 patients were examined, it was concluded that there was no significant difference in patient characteristics between the etomidate group $(n=18)$ and the fentanyl/midazolam group $(\mathrm{n}=12)$. The etomidate group had slightly higher blood cortisol levels than the fentanyl/midazolam group $(4.2 \pm 4.9 \mu \mathrm{g} / \mathrm{dL}$ vs. $11.2 \pm 6.1 \mu \mathrm{g} / \mathrm{dL}$, $p<0.001)$. In the group treated with etomidate, the duration of intensive care unit treatment was longer (8 days vs. 3 days, $p=0.011$ ), the duration of mechanical ventilation was longer ( 6.3 days vs. 1.5 days, $p=0.007$ ), and the duration of inpatient treatment was longer (14 days vs. 6 days, $p=0.007$ ). During the study period, two trauma patients in the etomidate group died. The authors concluded that sedation-inducing drugs like etomidate should be considered in patients with severe trauma.

A retrospective study conducted in 2016 reported no significant difference in hospital mortality between etomidate and ketamine (17.3\% vs. $20.4 \%$; adjusted OR 0.80 ; 95\% CI 0.92-2.16) in 968 patients treated with etomidate $(\mathrm{n}=526)$ or ketamine $(\mathrm{n}=442)$, In addition, the duration of admission to the intensive care unit and duration of mechanical ventilation were similar in each group [40]. Previous data have shown unfavorable results for the use of etomidate in severe trauma patients, but a recent study that compared etomidate to ketamine showed contradictory results. Both ketamine and etomidate can be used in trauma patients. However, etomidate should be used carefully and adrenal function decline must be monitored.

\section{Acceptability and applicability}

Etomidate, ketamine, and similar sedative drugs are widely used as induction drugs during intubation. The use of etomidate and ketamine during intubation is not difficult to apply and is deemed acceptable.

\section{IF CERVICAL SPINE DAMAGE IS SUS- PECTED, HOW IS CERVICAL PROTECTION ACHIEVED DURING AIRWAY INTUBA- TION?}

\section{Recommendation}

When intubating a patient with a cervical spine injury, the extraction collar can be temporarily removed while the neck is fixed and protected manually (1C).

\section{Evidence summary}

Generally, in trauma patients with multiple injuries, cervical spine fixation is performed until cervical spine fractures can be excluded though imaging. However, if the cervical spine fixation device is properly put in place, the cervical spine fixation device makes it difficult to adjust the angle of the head. This inhibits the opening of the oral cavity, which is disadvantageous for laryngoscope intubation. A prospective multicenter study confirmed that cervical spine fixation was a cause for difficulty during intubation [41]. In order to avoid difficulties in airway intubation, medical staff around the globe use manual inline stabilization (MILS) instead of spinal fixation.

When MILS is performed, the assistant medical staff must manually fix the spine using both hands. The insertion of a laryngoscope using manual alignment stabilization has been the standard of care in emergency situations for many years. However, controversy remains regarding the manual alignment stabilization method, and negative effects have also been reported [42,43]. As an alternative 
to direct laryngoscopy, fiber-optic laryngoscopy can be used by experienced medical staff as a standard testing method when the patient has stable cardiopulmonary function and spontaneous breathing $[3,44]$.

\section{Acceptability and applicability}

This technique is not difficult to apply and is thus deemed acceptable for application.

\section{WHAT ALTERNATIVE METHOD SHOULD BE USED IF SECURING THE AIRWAYS FAILS MORE THAN THREE TIMES?}

\section{Recommendation}

If three or more attempts to intubate the airway fail, other methods should be considered to secure the airway (1B).

\section{Evidence summary}

The number of attempted airway intubations is significantly higher for trauma patients than for non-traumatic patients [45]. It was reported that $85.4 \%$ of intubations were successful in the first attempt, while $2.7 \%$ required a second attempt. For $1.5 \%$ of cases, other methods of intubation were applied after a third failure. A system for airway intubation must be implemented in order to devise a fail-safe system when intubation fails multiple times [46]. In a retrospective study of 2,833 patients, it was reported that airway-related complications increased significantly when two or more airway intubation attempts were required [47]. In a prospective multicenter study conducted over 18 months, $30 \%$ of 1,941 airway intubations required more than one attempt, and did not exceed six attempts. The cumulative success rate was $70 \%$ for the first attempt, $85 \%$ for the second attempt, and $90 \%$ for the third attempt [48]. It is essential to consider alternative methods after three attempts of airway intubation $[47,49]$.

\section{Acceptability and applicability}

The above guideline is deemed acceptable for domestic application.

\section{SHOULD TRAUMA PATIENTS MAINTAIN NORMAL VENTILATION AFTER INTUBA- TION?}

\section{Recommendation}

It is recommended that trauma patients who have undergone airway intubation maintain normal ventilation rather than hyperventilation or hypoventilation (1C).

\section{Evidence summary}

Multiple studies have shown that maintaining normal ventilation is associated with a better prognosis than performing hyperventilation or hypoventilation, which is particularly evident in patients with brain injury. In addition, with the exception of patients with chest injuries, it is helpful to measure the partial pressure of carbon dioxide at the end of an expiration to maintain and monitor normal ventilation [50-53].

Recently, there has been a tendency to use permissive hypotension in hypovolemic hypotension patients, but only animal studies have been conducted on this issue [54]. In the guidelines published by Bratton et al., the treatment guidelines for brain injury patients were revised in 2017, but there were no changes in this topic [55]. The military trauma guidelines published in 2017 also recommend that hypoventilation and hyperventilation should be avoided in patients with brain injury [56].

\section{Acceptability and applicability}

The above guideline is deemed acceptable for domestic application.

\section{WHEN SHOULD RESUSCITATIVE THORA- COTOMY BE CONSIDERED FOR TRAUMA PATIENTS?}

\section{Recommendation}

Resuscitative thoracotomy is recommended for trauma patients with penetrating injuries undergoing cardiac arrest or shock in the emergency room (1B).

\section{Evidence summary}

Resuscitative thoracotomy may be performed in cases 
of severe shock, pericardial pressure, loss of peripheral pulse, or cardiac arrest [57-59]. However, the indications and outcomes of resuscitative thoracotomy depend on the type of injury and the presence or absence of survival signs. Survival signs are defined as the pupil reflex, spontaneous breathing, movement in response to pain stimuli, or electrical activity of the heart $[57,58]$. In one meta-analysis, the survival rate for patients who underwent resuscitation thoracotomy after experiencing penetrating injuries was reported to be $11.2 \%$ [57]. Jahangiri et al. [60] reported that patients with favorable vital signs had a good prognosis without neurological defects when thoracotomy was performed. Accordingly, the researchers noted that thoracotomy should be performed in patients with penetrating injuries who have favorable vital signs at the site of injury or in the emergency room.

According to a report that compared the outcomes of 959 patients with penetrating injuries who underwent resuscitation thoracotomy in the emergency room for 26 years, patients who did not exceed 15 minutes of cardiopulmonary resuscitation (CPR) or 5 minutes of cardiac arrest had a fair survival rate. The paper advised that thoracotomy should not be performed in patients without detectable vital signs [61]. However, for patients without a known time of cardiac arrest, thoracotomy should be performed depending on the situation [59]. Therefore, it is recommended that thoracotomy should be performed in patients with penetrating injuries with vital signs when cardiac arrest occurs $[57,59,60]$.

Although it was reported that blunt trauma patients who did not exceed 10 minutes of CPR had a significant chance of being resuscitated, it was also advised that thoracotomy should not be performed on patients undergoing cardiac arrest unaccompanied by cardiac tamponade [62-65]. In addition, thoracotomy is not recommended for blunt trauma patients with multiple injuries because the survival outcomes are quite low and there is a meaningful possibility of complications involving neurological disorders or brain death [59]. In conclusion, thoracotomy should be considered depending on the situation. Thoracotomy should be performed in blunt injury patients with favorable vital signs. In blunt injury patients with cardiac arrest or no vital signs, thoracotomy is not indicated $[59,66]$.
Resuscitative endovascular balloon occlusion of the aorta (REBOA) is a method of resuscitation that uses a balloon to close off the aorta, reducing the amount of bleeding and temporarily redistributing the blood flow to the brain and heart. In a study that examined 76 trauma patients for 5 years, faster REBOA application increased the survival rate by stabilizing hemodynamics. In that study, 46 people (61\%) survived the initial 24 hours and $35(46 \%)$ were discharged. In order not to delay treatment, it is helpful to initiate REBOA within an average of 60 minutes from arrival and to do REBOA before cardiac arrest occurs. And to perform partial occlusion within 30 minutes in order to maintain a systolic blood pressure above $90 \mathrm{mmHg}$ [67]. In another study that compared two groups (aortic cross-clamping [ACC] vs. REBOA) that were divided by propensity score matching, the latter group had a lower survival rate. However, the study was inconclusive, as higher degrees of chest injuries were observed in the ACC group, while the abdominal or intrapelvic arterial embolization ratio was higher in the REBOA group [68]. According to a multicenter prospective observational study of the aortic occlusion for resuscitation in trauma and acute care surgery registry of 114 patients (46 REBOA, 68 ACC), there was no statistically significant difference in survival rate between the ACC group (57/68; 83.8\%) and the REBOA group (33/46; $71.7 \%$ ) [69]. However, a simple comparison would be inappropriate due to the skewed number of cardiac arrest patients in the ACC group. In conclusion, REBOA could be used instead of ACC in hemorrhagic shock patients with severe intraperitoneal bleeding or pelvic injury [6769].

\section{Acceptability and applicability}

The domestic acceptance and applicability of the treatment guidelines are judged to be plausible. However, since the evidence for blunt injuries is controversial and the issue has not been well studied, the guidelines for penetrating injuries are only recommendations.

\section{REFERENCES}

1. Dunham CM, Barraco RD, Clark DE, Daley BJ, Davis FE 3rd, 
Gibbs MA, et al. Guidelines for emergency tracheal intubation immediately after traumatic injury. J Trauma 2003;55:162-79.

2. Deakin CD, Nolan JP, Soar J, Sunde K, Koster RW, Smith GB, et al. European resuscitation council guidelines for resuscitation 2010 section 4 . Adult advanced life support. Resuscitation 2010;81:1305-52.

3. Paal P, Herff H, Mitterlechner T, von Goedecke A, Brugger H, Lindner $\mathrm{KH}$, et al. Anaesthesia in prehospital emergencies and in the emergency room. Resuscitation 2010;81:148-54.

4. Badjatia N, Carney N, Crocco TJ, Fallat ME, Hennes HM, Jagoda AS, et al. Guidelines for prehospital management of traumatic brain injury 2nd edition. Prehospital Emergency Care 2008;12(Suppl 1):S1-52.

5. Kortbeek JB, Al Turki SA, Ali J, Antoine JA, Bouillon B, Brasel $\mathrm{K}$, et al. Advanced trauma life support, 8th edition, the evidence for change. J Trauma 2008;64:1638-50.

6. Chesnut RM. Avoidance of hypotension: conditio sine qua non of successful severe head-injury management. J Trauma 1997;42(5 Suppl):S4-9.

7. Chesnut RM, Marshall LF, Klauber MR, Blunt BA, Baldwin N, Eisenberg HM, et al. The role of secondary brain injury in determining outcome from severe head injury. J Trauma 1993;34:216-22.

8. Jeremitsky E, Omert L, Dunham CM, Protetch J, Rodriguez A. Harbingers of poor outcome the day after severe brain injury: hypothermia, hypoxia, and hypoperfusion. J Trauma 2003;54:312-9.

9. Stahel PF, Smith WR, Moore EE. Hypoxia and hypotension, the "lethal duo" in traumatic brain injury: implications for prehospital care. Intensive Care Med 2008;34:402-4.

10. Stocchetti N, Furlan A, Volta F. Hypoxemia and arterial hypotension at the accident scene in head injury. J Trauma 1996;40:764-7.

11. Klemen P, Grmec S. Effect of pre-hospital advanced life support with rapid sequence intubation on outcome of severe traumatic brain injury. Acta Anaesthesiol Scand 2006;50:1250-4.

12. Suominen P, Baillie C, Kivioja A, Ohman J, Olkkola KT. Intubation and survival in severe paediatric blunt head injury. Eur J Emerg Med 2000;7:3-7.

13. Frankel H, Rozycki G, Champion H, Harviel JD, Bass R. The use of TRISS methodology to validate prehospital intubation by urban EMS providers. Am J Emerg Med 1997;15:630-2.

14. Bernard S, Smith K, Foster S, Hogan P, Patrick I. The use of rapid sequence intubation by ambulance paramedics for patients with severe head injury. Emerg Med (Fremantle) 2002;14:40611.

15. Berlac P, Hyldmo PK, Kongstad P, Kurola J, Nakstad AR, Sandberg M; Scandinavian Society for Anesthesiology and Intensive Care Medicine. Pre-hospital airway management: guidelines from a task force from the Scandinavian Society for Anaesthesiology and intensive care medicine. Acta Anaesthesiol Scand 2008;52:897-907.

16. Bochicchio GV, Ilahi O, Joshi M, Bochicchio K, Scalea TM. Endotracheal intubation in the field does not improve outcome in trauma patients who present without an acutely lethal traumatic brain injury. J Trauma 2003;54:307-11.

17. Davis DP, Hoyt DB, Ochs M, Fortlage D, Holbrook T, Marshall LK, et al. Davis DP, Hoyt DB, Ochs M, et al. The effect of paramedic rapid sequence intubation on outcome in patients with severe traumatic brain injury. J Trauma 2003;54:444-53.

18. DiRusso SM, Sullivan T, Risucci D, Nealon P, Slim M. Intubation of pediatric trauma patients in the field: predictor of negative outcome despite risk stratification. J Trauma 2005;59:84-91.

19. Lecky F, Bryden D, Little R, Tong N, Moulton C. Emergency intubation for acutely ill and injured patients. Cochrane Database Syst Rev 2008;2008:CD001429.

20. Liberman M, Roudsari BS. Prehospital trauma care: what do we really know?. Curr Opin Crit Care 2007;13:691-6.

21. Murray JA, Demetriades D, Berne TV, Stratton SJ, Cryer HG, Bongard F, et al. Prehospital intubation in patients with severe head injury. J Trauma 2000;49:1065-70.

22. von Elm E, Schoettker P, Henzi I, Osterwalder J, Walder B. Pre-hospital tracheal intubation in patients with traumatic brain injury: systematic review of current evidence. Br J Anaesth 2009;103:371-86.

23. Wang HE, Sweeney TA, O'Connor RE, Rubinstein H. Failed prehospital intubations: an analysis of emergency department courses and outcomes. Prehosp Emerg Care 2001;5:134-41.

24. Ruchholtz S, Waydhas C, Ose C, Lewan U, Nast-Kolb D; Working Group on Multiple Trauma of the German Trauma Society. Prehospital intubation in severe thoracic trauma without respiratory insufficiency: a matched-pair analysis based on the Trauma Registry of the German Trauma Society. J Trauma 2002;52:879-86.

25. NAEMT. Präklinisches Traumamanagement: Das PHTLS-Konzept. München: Elsevier; 2009.

26. Rivara FP, Maier RV, Mueller BA, et al. Evaluation of potentially preventable deaths among pedestrian and bicyclist fatalities. 
JAMA 1989;261:566-70.

27. Cudnik MT, Newgard CD, Wang H, Bangs C, Herringtion R 4th. Endotracheal intubation increases out-of-hospital time in trauma patients. Prehosp Emerg Care 2007;11:224-9.

28. Trupka A, Waydhas C, Nast-Kolb D, Schweiberer L. Effect of early intubation on the reduction of post-traumatic organ failure. Unfallchirurg 1995;98:111-7.

29. Ruchholtz S, Lefering R, Paffrath T, Oestern HJ, Neugebauer E, Nast-Kolb D, et al. Reduction in mortality of severely injured patients in Germany. Dtsch Arztebl Int 2008;105:225-31.

30. Mayglothling J, Duane TM, Gibbs M, McCunn M, Legome E, Eastman AL, et al. Emergency tracheal intubation immediately following traumatic injury: an Eastern Association for the Surgery of Trauma practice management guideline. J Trauma Acute Care Surg 2012;73(5 Suppl 4):S333-40.

31. Sunde GA, Sandberg M, Lyon R, Fredriksen K, Burns B, Hufthammer KO, et al. Hypoxia and hypotension in patients intubated by physician staffed helicopter emergency medical services - a prospective observational multi-centre study. BMC Emerg Med 2017;17:22.

32. Walls RM, Brown CA 3rd, Bair AE, Pallin DJ; NEAR II Investigators. Emergency airway management: a multi-center report of 8937 emergency department intubations. J Emerg Med 2011;41:347-54.

33. Miraflor E, Chuang K, Miranda MA, Dryden W, Yeung L, Strumwasser A, et al. Timing is everything: delayed intubation is associated with increased mortality in initially stable trauma patients. J Surg Res 2011;170:286-90.

34. Lossius HM, Røislien J, Lockey DJ. Patient safety in pre-hospital emergency tracheal intubation: a comprehensive meta-analysis of the intubation success rates of EMS providers. Crit Care 2012;16:R24

35. Mort TC. Esophageal intubation with indirect clinical tests during emergency tracheal intubation: a report on patient morbidity. J Clin Anesth 2005;17:255-62.

36. Wang HE, Yealy DM. How many attempts are required to accomplish out-of-hospital endotracheal intubation?. Acad Emerg Med 2006;13:372-7.

37. Eckstein M, Chan L, Schneir A, Palmer R. Effect of prehospital advanced life support on outcomes of major trauma patients. J Trauma 2000;48:643-8.

38. Warner KJ, Cuschieri J, Jurkovich GJ, Bulger EM. Single-dose etomidate for rapid sequence intubation may impact outcome after severe injury. J Trauma 2009;67:45-50.
39. Hildreth AN, Mejia VA, Maxwell RA, Smith PW, Dart BW, Barker DE. Adrenal suppression following a single dose of etomidate for rapid sequence induction: a prospective randomized study. J Trauma 2008;65:573-9.

40. Upchurch CP, Grijalva CG, Russ S, Collins SP, Semler MW, Rice TW, et al. Comparison of etomidate and ketamine for induction during rapid sequence intubation of adult trauma patients. Ann Emerg Med 2017;69:24-33.e2.

41. Lackner CK, Reith MW, Ruppert M, Netzsch C, Widmann JH, Hofmann-Kiefer K, et al. Prähospitale Intubation und Verifizierung der endotrachealen Tubuslage. Notfall \& Rettungsmedizin 2002;5:430-440.

42. Manoach S, Paladino L. Manual in-line stabilization for acute airway management of suspected cervical spine injury: historical review and current questions. Ann Emerg Med 2007;50:23645.

43. Santoni BG, Hindman BJ, Puttlitz CM, Weeks JB, Johnson N, Maktabi MA, et al. Manual in-line stabilization increases pressures applied by the laryngoscope blade during direct laryngoscopy and orotracheal intubation. Anesthesiology 2009;110:2431.

44. Bonhomme V, Hans P. Management of the unstable cervical spine: elective versus emergent cases. Curr Opin Anaesthesiol 2009;22:579-85.

45. Thierbach A, Piepho T, Wolcke B, Küster S, Dick W. Prehospital emergency airway management procedures. Success rates and complications. Anaesthesist 2004;53:543-50.

46. Keul W, Bernhard M, Völkl A, Gust R, Gries A. Methods of airway management in prehospital emergency medicine. Anaesthesist 2004;53:978-92.

47. Mort TC. Emergency tracheal intubation: complications associated with repeated laryngoscopic attempts. Anesth Analg 2004;99:607-13.

48. Wang HE, Yealy DM. How many attempts are required to accomplish out-of-hospital endotracheal intubation?. Acad Emerg Med 2006;13:372-7.

49. American Society of Anesthesiologists Task Force on Management of the Difficult Airway. Practice guidelines for management of the difficult airway: an updated report by the American Society of Anesthesiologists Task Force on Management of the Difficult Airway. Anesthesiology 2003;98:1269-77.

50. Brain Trauma Foundation; American Association of Neurological Surgeons; Congress of Neurological Surgeons; Joint Section on Neurotrauma and Critical Care, AANS/CNS, Bratton 
SL, et al. Guidelines for the management of severe traumatic brain injury. IX. Cerebral perfusion thresholds. J Neurotrauma 2007;24(Suppl 1):S59-64.

51. Bullock MR, Povlishock JT. Guidelines for the management of severe traumatic brain injury. Editor's Commentary. J Neurotrauma 2007;24(Suppl 1):2-S1.

52. Caulfield EV, Dutton RP, Floccare DJ, Stansbury LG, Scalea TM. Prehospital hypocapnia and poor outcome after severe traumatic brain injury. J Trauma 2009;66:1577-83.

53. Warner KJ, Cuschieri J, Copass MK, Jurkovich GJ, Bulger EM. Emergency department ventilation effects outcome in severe traumatic brain injury. J Trauma 2008;64:341-7.

54. Taghavi S, Jayarajan SN, Ferrer LM, Vora H, McKee C, Milner $\mathrm{RE}$, et al. "Permissive hypoventilation" in a swine model of hemorrhagic shock. J Trauma Acute Care Surg 2014;77:14-9.

55. Carney N, Totten AM, O'reilly C, Ullman JS, Hawryluk GW, Bell MJ, et al. Guidelines for the management of severe traumatic brain injury, fourth edition. Neurosurgery 2017;80:6-15.

56. Otten EJ, Dorlac WC. Managing traumatic brain injury: translating military guidelines to the wilderness. Wilderness \& Environmental Medicine 2017;28(Suppl 2):S1-154.

57. Working Group, Ad Hoc Subcommittee on Outcomes, American College of Surgeons. Committee on Trauma. Practice management guidelines for emergency department thoracotomy. Working Group, Ad Hoc Subcommittee on Outcomes, American College of Surgeons-Committee on Trauma. J Am Coll Surg 2001;193:303-9.

58. Boyd M, Vanek VW, Bourguet CC. Emergency room resuscitative thoracotomy: when is it indicated?. J Trauma 1992;33:71421.

59. Seamon MJ, Haut ER, Van Arendonk K, Barbosa RR, Chiu WC, Dente CJ, et al. An evidence-based approach to patient selection for emergency department thoracotomy: a practice management guideline from the Eastern Association for the Surgery of Trauma. J Trauma Acute Care Surg 2015;79:159-73.

60. Jahangiri M, Hyde J, Griffin S, Magee P, Youhana A, Lewis T, et al. Emergency thoracotomy for thoracic trauma in the accident and emergency department: indications and outcome. Ann R Coll Surg Engl 1996;78(3 ( Pt 1)):221-4.

61. Powell DW, Moore EE, Cothren CC, et al. Is emergency department resuscitative thoracotomy futile care for the critically injured patient requiring prehospital cardiopulmonary resuscitation?. J Am Coll Surg 2004;199:211-5.

62. Fialka C, Sebök C, Kemetzhofer P, Kwasny O, Sterz F, Vécsei V. Open-chest cardiopulmonary resuscitation after cardiac arrest in cases of blunt chest or abdominal trauma: a consecutive series of 38 cases. J Trauma 2004;57:809-14.

63. Pickens JJ, Copass MK, Bulger EM. Trauma patients receiving CPR: predictors of survival. J Trauma 2005;58:951-958.

64. Seamon MJ, Fisher CA, Gaughan JP, Kulp H, Dempsey DT, Goldberg AJ. Emergency department thoracotomy: survival of the least expected. World J Surg 2008;32:604-12.

65. Sheppard FR, Cothren CC, Moore EE, Orfanakis A, Ciesla DJ, Johnson JL, et al. Emergency department resuscitative thoracotomy for nontorso injuries. Surgery 2006;139:574-6.

66. Velmahos GC, Degiannis E, Souter I, Allwood AC, Saadia R. Outcome of a strict policy on emergency department thoracotomies. Arch Surg 1995;130:774-7.

67. Matsumura Y, Matsumoto J, Kondo H, Idoguchi K, Funabiki T; DIRECT-IABO investigators. Partial occlusion, conversion from thoracotomy, undelayed but shorter occlusion: resuscitative endovascular balloon occlusion of the aorta strategy in Japan. Eur J Emerg Med 2018;25:348-54.

68. Abe T, Uchida M, Nagata I, Saitoh D, Tamiya N. Resuscitative endovascular balloon occlusion of the aorta versus aortic cross clamping among patients with critical trauma: a nationwide cohort study in Japan. Crit Care 2016;20:400.

69. DuBose JJ, Scalea TM, Brenner M, Skiada D, Inaba K, Cannon $\mathrm{J}$, et al. The AAST prospective aortic occlusion for resuscitation in trauma and acute care surgery (AORTA) registry: data on contemporary utilization and outcomes of aortic occlusion and resuscitative balloon occlusion of the aorta (REBOA). J Trauma Acute Care Surg 2016;81:409-19. 